\title{
Neurociencia y derecho: problemas y posibilidades para el quehacer jurídico
}

\author{
Neuroscience and law: Problems and possibilities for the legal \\ aspects
}

\author{
Ronald Cárdenas Krenz \\ Universidad de Lima, Lima, Perú \\ Recibido el 20 de septiembre de 2016; aceptado el 6 de diciembre de 2016
}

\section{Resumen}

El artículo trata sobre la relación entre la neurociencia y el derecho, analizando los alcances de esta nueva disciplina para el quehacer jurídico. Dado que diversos estudios del cerebro cuestionan la existencia del libre albedrío, y que este es base del principio jurídico de la autonomía de la voluntad, se analiza si realmente existe o no, cuestión esencial para el derecho. Se revisan, asimismo, las posibilidades que ofrece la neurociencia para contar con nuevos medios para buscar la verdad, el desarrollo del marketing, la determinación de la capacidad y otros temas, pasando revista tanto a diversos beneficios como a riesgos. Finalmente, se aborda la necesidad de velar por que se garantice el respeto de los derechos humanos frente al desarrollo de las nuevas tecnologías neurocientíficas.

Abstract: This article is about the connection between neuroscience and the effects on legal rules. There are several brain studies that question the existence of free will. Free will is the basis of legal docrine. This article attempts to determine whether or not free will exists, and to review the possibilities offered by neuroscience, with new means to seek the truth, marketing development, determination of capacity and other issues, by reviewing the benefits and risks. Finally, it addresses the need to ensure the respect of human rights with these new neuroscientific technologies.

Correo electrónico: ronald@unife.edu.pe 


\section{Introducción}

Entre el 2009 y el 2013, se publicaron en el mundo 1.790 .000 artículos sobre neurociencia, con lo que la proporción que ocupa la investigación neurocientífica en las publicaciones científicas llegó a un 16\% ${ }^{1}$. En España, el Parlamento declaró el 2012 como el año de las neurociencias, mientras en Estados Unidos el presidente Busch declaró a los años 90 como la «Década del Cerebro» ${ }^{2}$. En 15 años, hemos aprendido de nuestro cerebro más que en toda la historia humana (Kaku, 2015, pp. 22-23).

El extraordinario desarrollo de la neurociencia nos está llevando a una nueva revolución científica, cambiando una serie de paradigmas. Gracias a ella, podemos entender cada vez más las bases neurológicas de nuestra conciencia y de la razón, la determinación de nuestras conductas y de nuestro $\mathrm{yo}^{3}$, las bases de la moralidad ${ }^{4}$, el proceso del pensamiento y de toma de decisiones, el funcionamiento del sistema nervioso, el enfrentamiento de trastornos como el autismo, el alzheimer o la esquizofrenia, etc.

La tecnología nos ofrece diversas ventanas para ingresar al cerebro, a fin de visualizar distintos aspectos de su funcionamiento, sin necesidad de abrirlo o apelar a otros medios riesgosos, pues puede ser representado a través de complejas técnicas, conocidas por los acrónimos de TAC, PET, MRI y MRA (Restak, 2005, p. 17).

Sin embargo, todavía existe un amplio territorio por explorar: el 20 de julio del 2016, la revista Nature dio a conocer un nuevo mapa que identifica 180 regiones conocidas del córtex cerebral, de las cuales 97 eran desconocidas. El trabajo fue hecho por un equipo de neurocientíficos de la Universidad de Washington en San Luis, junto con otros centros estadounidenses, en el marco del proyecto Human Conectome.

\footnotetext{
${ }^{1}$ Elsevier Brain Research Report (2014, p. 3).

${ }^{2}$ La Unión Europea tiene el Human Brain Proyect, con un financiamiento de 1.000 millones de euros. Estados Unidos tiene el proyecto Brain Activity Map, con un estimado de 300 millones de dólares durante 10 años. Otro proyecto relevante es el Human Connectome Project, que tiene por fin construir un mapa de redes sobre la conectividad anatómica y funcional del cerebro, patrocinado por los National Institutes of Health.

3 «La neurociencia nos proporciona una oportunidad nueva y única para comprender la estructura y funciones del yo, no solo observando la conducta desde el exterior, sino también gracias al estudio del funcionamiento interno del cerebro» (García García, 2014, p. 44).

${ }^{4}$ Naturalmente que en este rubro debemos ser cautos, pues la moralidad no puede reducirse a mera biología; Churchland (2012, p. 14) advierte, precisamente sobre «la lógica absurdidad de basarnos en las ciencias biológicas para entender la base de la moralidad».
} 
La amplitud de los alcances de la neurociencia ha dado lugar al surgimiento de términos como neurofilosofía, neuropedagogía, neuroética, neuromarketing, neuropolítica, neuroeconomía, neuroestética y neuroderecho, neuroética, neuromarketing, neuropolítica, neuroeconomía, neuroestética y neuroderecho, entre otros, aunque debe observarse que, en esta última área, los estudios siguen siendo todavía limitados, al menos en nuestro medio, no obstante que, el poder explicar mejor nuestras conductas y cómo se relaciona nuestra razón con nuestras emociones, puede ser fundamental para el análisis jurídico y la determinación de responsabilidades ${ }^{5}$.

Siguiendo a Narváez, es a partir del año 2008 que, dejando de lado algunas ideas poco claras sobre su naturaleza, el neuroderecho (o neurolaw, en inglés) se entenderá como «la reflexión sobre la forma y el alcance en que múltiples facetas de la comprensión, producción y aplicación del derecho se verán afectadas por el estudio empírico del cerebro en la medida en que este se considera parte central de la explicación de la conducta» (Narváez Mora, 2014, p. 128).

La relación entre derecho y neurociencia implica diversos aspectos, que generan diversos efectos algunos positivos, otros, negativos y, en otros casos, simplemente las cosas se encuentran en el plano de la incertidumbre, una vez sacados de la comodidad de los viejos paradigmas en los que solemos reposar ${ }^{6}$.

La neurociencia puede ser de gran utilidad para el derecho, al permitir calificar de manera más certera la conducta humana, saber si una persona dice la verdad o no, o facilitar nuevas herramientas a algunos discapacitados para un mejor ejercicio de sus derechos ${ }^{7}$.

\footnotetext{
${ }^{5}$ Vale tener en cuenta con Venegas (2012) que «... el sistema jurídico ha creado su propio concepto de voluntad, partiendo de la libertad y ha estado totalmente al margen de las discusiones y los avances que sobre el funcionamiento del cerebro se han generado».

${ }^{6}$ «. . el surgimiento de las neurociencias frente a fenómenos como la justicia o la conducta criminal nos ha sumergido en un mar de incertidumbres, y nos ha sacado de un cómodo lugar desde el que parecía más fácil condenar o absolver» (Gutiérrez de Piñeres, 2013, p. 10).

7 Paul Marasco, Investigador del Departamento de Biotecnología de la Cleveland Clinic (EE. UU.), explicaba durante una visita a Lima en junio del 2016 que, desde el 2011, se han podido desarrollar tecnologías que permiten el control mental para el movimiento, que proveen del sentido del tacto a las prótesis y permiten que el cerebro piense que ese miembro artificial es parte del cuerpo; para el efecto, se trabaja con los nervios periféricos, fuera del cerebro; entonces, no es necesaria la «conversación» con el cerebro, sino que se hace directamente con los músculos; es decir, se provee de información al cerebro para que crea que está sucediendo algo que no está sucediendo (Suárez Bolesman, 2016). Ya es posible colocar un chip a un paciente con parálisis para que a través de su cerebro pueda navegar por internet, mandar e-mails, controlar su silla de ruedas, operar electrodomésticos y controlar brazos mecánicos; ello aparte de los exoesqueletos (Kaku, 2015, p. 26). En el 2016, se conoció la creación de un pequeño dispositivo, llamado «estentrodo» — del tamaño de un chip_ que facilita a las personas con parálisis que puedan mover los pies con la mente, elaborado por científicos del Instituto Florey de Neurociencia y Salud Mental, de la Universidad de Melbourne y del Hospital Real de Melbourne. Se dice que podría servir para el tratamiento de la epilepsia, Parkinson y otros trastornos neurológicos.
} 
Sin embargo, su aplicación puede propiciar también algunas amenazas contra derechos fundamentales como la libertad, la dignidad o la intimidad, a través de la manipulación de las personas ${ }^{8}$ para hacer que compren un producto o para inducir su voto, ingresando a sus centros de decisión o, inclusive, al permitir que nos introduzcamos en sus recuerdos ${ }^{9}$ o en sus propios pensamientos ${ }^{10}$.

Científicos del Instituto Karolinska, de Estocolmo, han llegado a hacer que una persona pueda sentirse ubicada en un cuerpo que no es el suyo, como por ejemplo en el de una muñeca «Barbie», sin necesidad de usar drogas ni otro tipo de manipulaciones. Esto se debe a que la percepción que tenemos de la ubicación de nuestro cuerpo la crea el cerebro, y es posible ahora crear la ilusión de estar en otro cuerpo. Ello determina que, si alguien pretendiera golpear nuestro cuerpo virtual, sentiríamos el mismo temor que si el ataque fuera sobre nuestro cuerpo real. La novedad es simpática si hablamos de juegos de realidad virtual en donde los «gamers» pueden experimentar estar en una montaña rusa o en una nave espacial, pero ¿qué hacer frente a otros usos perversos? ¿Qué pasaría si alguien es torturado «virtualmente», pero no físicamente? ¿Podríamos hablar estrictamente de tortura?

Todas estas cuestiones nos llevan al tema del impacto de la tecnología, la cual, a la vez de solucionar algunos problemas, puede generar otros, cuestión que demanda, a su vez, tener en cuenta la bioética a la hora de evaluar los últimos avances de la ciencia ${ }^{11}$, considerando que estos temas, más que asuntos médicos son asuntos trascendentalmente humanos. Como dijera Jonas: «... la técnica es un ejercicio del poder humano, es decir, una forma de actuación, y toda actuación humana está expuesta a su examen moral» (Jonas, 1997, p. 33).

\footnotetext{
${ }^{8}$ En los últimos años están empezando a conocerse programas de la CIA, como el Mkultra, que tiene por objeto aprender a manipular la mente del enemigo (Del Brío León, 2011, p. 17).

${ }^{9}$ Anota Wolf — citando una publicación de Psychological Science, vol. 26, pp. 291-301, 2015- que es posible falsear los recuerdos en la memoria de algunas personas, mencionando un reciente estudio de un equipo de psicólogos de Inglaterra y Canadá en el que mediante la técnica de la sugestión, los investigadores lograron hacer creer a un 70\% de un grupo de estudiantes que habían cometido un delito (Wolf, 2016, p. 30).

${ }^{10}$ La tecnología permite hoy que una persona pueda instalar en su teléfono una aplicación, llamada KishKish Lie Detector, que permite a los usuarios de Skype saber si una persona miente o no,. Por otro lado, investigadores vienen estudiando la posibilidad de modificar los recuerdos, en experimentos con animales, usando medicamentos y con la luz (Wolf, 2016, pp. 26 y ss.).

${ }^{11}$ Como dice Nevares-Muñiz, a efectos de elaborar un modelo de deliberación adjudicativa para atender asuntos vinculados con los avances de la ciencia y la tecnología, sobre todo que no cuentan con legislación positiva o jurisprudencia aplicable, debe tenerse en cuenta una perspectiva que integre el Derecho y la Bioética (Nevares-Muñiz, 2013, p. 125).
} 
Ello resulta más relevante si consideramos que «ciertos segmentos de la ética parecen haberse retirado del campo de batalla, habiendo perdido su pendón de valimiento y dejado todo abandonado, a lo que los mismos hombres de ciencia consideren suficiente» (Andruet, 2004, p. 23).

La libertad, sin dejar de reconocerse su carácter fundamental, ha sido objeto de múltiples debates, pero hoy el asunto se vuelve más relevante a partir del vertiginoso desarrollo que han alcanzado las nuevas tecnologías. Sabemos que nuestro libre albedrío está condicionado por nuestros genes y nuestros «memes» ${ }^{12}$, nuestras experiencias y nuestras circunstancias, nuestros valores y una complejidad de procesos físicos y químicos, cuestión que lleva a preguntarnos si podemos caer, por ello, en un determinismo para justificar nuestros actos.

Vivimos en un mundo que no hemos escogido, con circunstancias que no fueron elegidas por nosotros, como nuestro cuerpo, color, sexo, raza, nacionalidad, lugar, época, etc.; existe infinidad de factores genéticos, históricos, sociales, económicos, biológicos o culturales que influyen en nosotros, pero, como dice Savater: estamos en un mundo que no hemos elegido, sí, pero elegimos dentro de ese mundo; somos libres en un mundo de determinaciones (Savater, 2012, p. 86). El problema es determinar qué tan libres somos, qué tanto estamos predeterminados y, en todo caso, qué tanto podemos ser libres para decidir por sobre nuestras predeterminaciones.

Los recientes avances tecnológicos pueden ser útiles para desentrañar algunos de estos misterios, sustraerlos del ámbito de la metafísica y del error ${ }^{13}$, y para que ocupe un lugar central el libre albedrío: «De un lado, un conjunto de argumentos muy poderosos nos fuerzan a la conclusión de que el libre albedrío no tiene lugar en el universo. De otro, una serie de argumentos poderosos basados en hechos de nuestra experiencia nos inclina a la conclusión de que tiene que haber algo de libre albedrío, puesto que todos nosotros lo experimentamos continuamente» (Searle, 1994, p. 99).

\footnotetext{
12 Término que, como se sabe, fuera acuñado por Richard Dawkins, para referirse a nuestras unidades mínimas de herencia social o unidades de transmisión cultural.

13 Por ejemplo, la clasificación de los pacientes depresivos en la categoría de enfermos es un descubrimiento reciente que le debemos a la Neurociencia (Punset, 2011, p. 144).
} 
Llevados hoy a la discusión de su misma existencia, ello podría llevar, en el derecho, a una ampliación de los criterios de inimputabilidad, lo que genera enormes y delicados alcances que deben sopesarse con detenimiento.

Por ejemplo: si estudios difundidos en abril del 2016 en Estados Unidos demuestran que las personas impulsivas tienen menos materia gris en el cerebro, ¿debe ser ello considerado una atenuante a la hora de calificar su culpabilidad?

De otro lado, en Italia, según información difundida por The Journal of Psychology, en febrero del 2016, los científicos han logrado «educar» al cerebro para que asimile temporalmente un placebo como si fuera un fármaco (en este caso, específicamente lo hicieron con enfermos de Parkinson); la cuestión es si ello debe aprovecharse para recetar menos medicamentos a los pacientes ${ }^{14}$, lo cual los beneficiaría tanto en su economía como en su salud, al evitar la ingesta excesiva de pastillas.

\section{De compras con la neurociencia}

La aplicación de la neurociencia ha dado lugar a una nueva disciplina: el neuromarketing. Las empresas han descubierto que mediante vías más directas pueden llegar a los sentimientos de sus consumidores y, sobre todo, a sus decisiones (Estupinya, 2010) ${ }^{15}$.

El neuromarketing explica, por ejemplo, cómo es que en un lugar de venta de vinos, si ponen música francesa de fondo, es más probable que compremos vino francés, y si se la música es alemana, lo más probable es que compremos vino alemán (Berger, 2015, p. 48) ${ }^{16}$.

Creemos que compramos por un motivo, cuando en verdad compramos por otro (Álvarez del Blanco, 2011, p. 156) ${ }^{17}$.

\footnotetext{
${ }^{14}$ Fabrizio Benedetti, del Departamento de Neurociencia de la Universidad de Turín, explica que: «These findings show that is possible to teach neurons in the thalamus to respond to placebos (...). These findings may have profound implications and applications, because we can reduce drug intake by exploiting these learning mechanisms (...) means people would need to take less medication but yet obtain the same clinical benefit» (En: http://www.physoc.org/ press-release/2016/teaching-neurons-respond-placebos-potential-treatment-parkinson\%E2\%80\%99s).

15 Es curioso mencionar que, en Estados Unidos, una empresa empezó a comercializar un spray con oxitocina, llamado Liquid Trust, dirigido a los solteros en busca de pareja y a hombres de negocio que quieren transmitir confianza en sus reuniones.

16 Se trata de un citado estudio de Adrián North de 1997.

${ }^{17}$ Cuenta Álvarez que cuando la cadena Exxon On The Run aromatizó sus locales con esencia de café, sus ventas de este producto aumentaron un 55\%. En esa línea, ya existen cines impregnados con olor a pop corn, librerías que huelen a madera noble y canela, etc.
} 
Las marcas actúan en nosotros activando un sistema de recompensa que afecta nuestra percepción, de modo que tomar un café es más que simplemente tomar un café. Las empresas se esfuerzan por hacer que sus productos nos parezcan valiosos, y es así que somos capaces de pagar más por un café en Starbucks, aunque en verdad no sea el mejor. Berger cita un test hecho en el año 2011 por la revista Consumer Reports, de acuerdo con el cual el café de dicha compañía no era para los consumidores más rico que el del supermercado Walmart, que lo vende a mitad de precio (Berger, 2015, p. 45), pero igual preferían tomarlo en el primero.

Así, la toma de decisiones al comprar algo no es necesariamente producto de un proceso racional, sino básicamente emocional.

\section{Un espía en nuestro cerebro}

Las técnicas de la neuroimagen — que ofrecen ya espectaculares logros (Feijoo Sánchez, 2011, p. 57) ${ }^{18}$ — pueden servir para tratar diversos problemas, como ciertas alteraciones en el cerebro que tienen relación con la toma de decisiones, posponiendo a veces el interés propio en función del colectivo, o haciéndonos más severos al evaluar a otras personas (Gutiérrez de Piñeres, 2013). Sin embargo, también pueden ser usadas con fines de manipulación, pueden poner en riesgo la intimidad de las personas, o generar nuevas formas de discriminación o abuso.

En Estados Unidos, la tendencia de nuestro cerebro a «completar la información ausente» fue usada por Obama para hacer frente a las acusaciones de musulmán que le hacían durante la campaña electoral norteamericana (Estupinyá, 2010, p. 91); por otro lado, el «efecto ancla» explica cómo hacen así sus propuestas de incremento laboral los sindicalistas y empleadores.

\footnotetext{
18 «Las neurociencias, en gran medida gracias a las enormes posibilidades que ofrecen los nuevos métodos de experimentación y neuroimagen - tomografía por emisión de positrones (PET), resonancia magnética funcional o nuclear (RM o fMRI), magnetoencefalografía, etc.- , han sufrido un avance espectacular en los últimos años y nos han abierto la ilusionante posibilidad de conocer mejor lo que denominamos "naturaleza humana"». La fMRI, al permitir apreciar los cambios en el flujo sanguíneo del cerebro cuando realizamos una tarea determinada, ofrece una visión no solo anatómica sino también funcional, que nos permite saber qué pasa allí en el mismo momento en que está pasando (Narváez Mora, 2012, p. 203).
} 


\section{Próximas ofertas en la farmacia}

Los fármacos ya no solo sirven para curarnos volviéndonos a la normalidad, sino para alterarla. El paradigma de que la medicina sirve para curar va cediendo cada vez más el paso a una medicina del deseo, que da nuevos moldes a nuestra personalidad.

«... en el futuro los conocimientos de genómica permitirán a las compañías farmacéuticas diseñar fármacos específicos según el perfil genético de cada paciente y minimizar considerablemente los efectos secundarios no deseados. Las personas serias podrán volverse alegres; las introvertidas, extravertidas; se podrá adoptar una personalidad el miércoles y otra para el fin de semana. Ya nadie tendrá excusa para sentirse deprimido o desdichado» (Fukuyama, 2002, p. 27).

Ante el miedo a asumir nuestras responsabilidades y las consecuencias de nuestros actos, ya no tendremos que enfrentar a nuestra conciencia, bastará algo más sencillo, como ir a la farmacia.

El uso de fármacos ya no para curar, sino para mejorar el funcionamiento del cerebro o nuestras conductas, aun sin necesidad médica, genera casos como el de los investigadores de la Universidad Concordia de Montreal (Canadá), que han creado un aerosol, con la oxitocina como componente principal, que ayudaría a enfrentar la timidez, para fomentar la extroversión y mejorar la confianza personal. La noticia fue difundida en diciembre de 2011 en la revista Psychophamarcology ${ }^{19}$.

\section{La gran pregunta: ¿existe la libertad?}

Los avances en neurociencia parecieran apuntar a que los seres humanos no somos tan libres como pensábamos. Dice Searle (1994, p. 98) que «parece realmente como si todo lo que sabemos sobre física nos forzase a una negación de la libertad humana», lo cual hace atractiva la tesis determinista. Sin embargo - agrega el mismo autor-, también tenemos que, frente a tal idea determinista, cuando hacemos algo tenemos la idea de que perfectamente podríamos haber actuado de modo distinto a como lo hicimos.

\footnotetext{
${ }^{19}$ Diversos científicos no excluyen que en el futuro se pueda llegar a tomar una píldora que motive la fidelidad o la monogamia, mediante un aumento de la oxitocina. En el 5. ${ }^{\circ}$ Congreso Brasileño del Cerebro, Comportamiento y Emociones, realizado el 2009 en Gramado (Brasil), se llegó a afirmar que, a futuro, un simple análisis de sangre bastará para saber si «hay química» entre 2 personas.
} 
Asumimos que somos seres libres y responsables. Todo sistema normativo, ya sea jurídico, ético o religioso, presupone — como apunta Evers (2010, p. 73) — que «los seres humanos tienen alguna capacidad de controlar voluntariamente su comportamiento o en cierta medida de influirlo». Sin embargo, ante las nuevas perspectivas de la neurociencia, aquella idea parece entrar en cuestionamiento:

«Cabe preguntarse si es razonable creer en el libre albedrío cuando aquello que experimentamos como una elección libre es el resultado de interacciones electroquímicas en el cerebro y una suerte de programa biológico para la toma de decisión modelada por la evolución. Pero, por otro lado, las ideas de libre albedrío y de responsabilidad personal funcionan como fundamentos sociales (...) ¿No sería absurdo y perversamente injusto mantener un sistema social sofisticado de recompensas y castigos si pensáramos que ninguna verdad ni realidad alguna corresponden a las nociones de mérito o culpabilidad?» (Evers, 2010, p. 16).

Por su parte, escribe Gazzaninga:

«.. mucha gente ha empezado a preocuparse por las viejas cuestiones del libre albedrío y la responsabilidad personal (. . .). El mundo físico está determinado, de modo que el cerebro también lo está. Si el cerebro está determinado (...) ¿están determinados también los pensamientos que surgen de la mente? ¿El libre albedrío que creemos tener es solo una ilusión? Y, si es una ilusión, ¿debemos revisar los conceptos relativos a la responsabilidad personal en las acciones?» (Gazzaniga, 2006, p. 100).

Mas si la libertad es una ilusión, ¿por qué parece que somos incapaces de abandonarla? Porque ella está ligada a la conciencia y solo atribuimos responsabilidad a los seres conscientes, dice Searle (1994, p. 106). Pero, ¿cuál es la fuente de nuestra inquebrantable convicción de nuestro libre albedrío? «la convicción, válida o inválida, de que podríamos estar haciendo algo distinto perfectamente aquí y ahora ...» (Searle, 1994, p. 107).

Empero, para autores como Evers (2010, p. 74), la explicación aún sería insuficiente, pues la idea de que actuamos voluntariamente — es decir, que podríamos haber actuado de otro modo- sería vaga e imprecisa. 


\section{De paseo por los tribunales: lo que la neurociencia puede contarnos de la administración de justicia}

Si no somos tan libres como pensábamos, y el principio de autonomía de la voluntad es la base del derecho, habría que replantearnos cuestiones fundamentales, considerando que «los neurocientíficos vienen demostrando que muchas de las bases filosóficas sobre las que se ha ido construyendo durante siglos el sistema de imputación jurídico-penal son erróneas» (Feijoo Sánchez, 2011, p. 4).

«El Derecho Penal hegemónico se basa en la idea de que las personas son racionales y gozan de libertad para decidir (...) si se comprueba que el libre albedrío no existe, esto pone en jaque directamente el presupuesto de imputación del Derecho Penal hegemónico (. . .) el libre albedrío es una condición sine qua non para que una persona pueda ser declarada culpable de una conducta criminal» (Symington, 2012, p. 69-70).

Por otro lado, la neurociencia ofrece interesantes posibilidades para una mejor aplicación del derecho; así, para la búsqueda de la verdad, explica Antonio Damasio que: «Muchos comportamientos que consideramos malvados o terribles son perfectamente explicables por la forma en que está diseñado el cerebro y su interacción con el entorno» (Punset, 2011, p. 197). Las preguntas, no obstante, que se nos plantean entonces son: ¿hasta qué punto pueden justificarse (y no solo explicarse) dichos crímenes?, ¿cómo distinguir unos casos de otros?, ¿cómo hacer para no caer en peligrosas posturas deterministas?

El hombre es el ser que elige, y esa capacidad de elegir es la que nos hace sujetos tanto de la ética como del derecho, y asumir sus consecuencias. Pero, si estamos determinados por razones que escapan a nuestra decisión, «¿sería justo condenar a un hombre que ha asesinado a su esposa como consecuencia de una lesión en el cerebro? (...), ¿puede predecirse la reincidencia de una persona que ha estado privada de la libertad a partir de estudios de neuroimagen?, (. . ¿ ¿ es libre en realidad la persona de decidir lo que está a bien o está mal?, ¿la decisión de cometer un delito está sujeta a un control libre y consciente de su conducta?»(Gutiérrez de Piñeres, 2013).

Adicionalmente, ante la posibilidad de usar modernas herramientas para acceder al cerebro de una persona, podemos preguntarnos con Symington (2012, pp. 73-95): ¿qué tanto podemos hacerlo sin afectar derechos fundamentales?, ¿puede pedir un 
fiscal al juez una orden para inspeccionar el cerebro de una persona? ¿puede el poder punitivo obligar a una persona a someterse a un procedimiento de fMRI sin violar sus derechos constitucionales a la libertad de pensamiento y de conciencia, el principio de indubio pro reo y el derecho a no autoincriminarse? (Symington, 2012 p. 73). ¿Si sabemos que una persona tiene predisposición a la violencia, debería detenérsela cuando aún no ha cometido ningún delito?

No obstante las preguntas sin resolver, cabe decir que la neurociencia ya viene aplicándose en la práctica, aun cuando todavía en forma limitada. La primera sentencia europea en la que se redujo la pena a un asesino teniendo en cuenta su estado cerebral y genético, sobre la base de hipótesis neurocientíficas, fue en el 2009, en Italia, cuando un juez del Tribunal de Apelación de Trieste redujo la pena al argelino Abdelmalek Bayout, quien había asesinado a un colombiano.

Las defensas judiciales basadas en la neurociencia (escáneres cerebrales y otros medios) se vienen ya aplicando en un importante número en Estados Unidos ${ }^{20}$. Nita Farahany, de la Universidad de Duke, da cuenta, entre el 2005 y el 2012, de más de 1.500 resoluciones (Styx, 2014, p. 7).

En México, estudios sobre cerebros de homicidas han demostrado la relación que habría entre su actuar y algunas condiciones de sus cerebros (Jiménez Vélez y Robledo Toro, 2010, p. 11).

\section{«Conócete a ti mismo»: ¿qué sabe nuestro cerebro de nuestro cerebro?}

De acuerdo con Kandel (2007, p. 13), «la comprensión de la mente humana en términos biológicos se ha transformado en la tarea científica fundamental del siglo XXI». No obstante, la cuestión no es en absoluto sencilla, y es que - como anota Cardinali (2007, p. VII) — comprender y explicar las bases biológicas de la cognición y la emoción es uno de los mayores desafíos para el conocimiento.

\footnotetext{
${ }_{20}$ «No hace mucho, la mera presentación de un escáner cerebral en un proceso judicial daba pie a titulares. Ya no. Todos los años se emplean las ciencias de la mente y el cerebro en cientos de decisiones judiciales para fundamental la resolución. No solo se recurre a escáneres cerebrales, sino a un abanico de estudios probatorios de que ciertas áreas del cerebro, como la amígdala o la corteza cingulada anterior están implicadas en tal o cual respuesta» (Styx, 2014, p. 7).
} 
Hasta hace solo unos años, se pensaba que nuestras neuronas no podían cambiar ni regenerarse con el tiempo, mas hoy sabemos que cuentan con las características de la plasticidad. Viejas ideas se derrumban y aparecen otras nuevas ${ }^{21}$, incluyendo el prometedor descubrimiento de la neurogénesis ${ }^{22}$.

Sabemos que el neocórtex controla las pulsaciones, cómo reaccionamos y nos relacionamos con el entorno, y cómo un daño físico en nuestro cerebro puede repercutir en lo conductual: es emblemático el famoso accidente de Phineas Gage $(1823-1860)^{23}$. El hecho constituiría un hito, como luego lo han sido la fundación de la Society for neuroscience (1970), el nacimiento oficial de la neuroética a partir de un evento académico en San Francisco (2002), la publicación del «Dar Manifiest» en Alemania (2014), etc. (Narváez Mora, 2014, p. 128) ${ }^{24}$.

Si bien el famoso caso de Phineas Gage contribuyó a sedimentar la idea de la existencia de una correlación entre el funcionamiento del lóbulo frontal y la conducta ética de las personas, será recién con el uso de la neuroimagen, años más tarde, cuando se han podido ubicar de mejor manera las zonas del cerebro vinculadas con cuestiones de personalidad. Puede apreciarse — siguiendo a Damasio, citado por Narváez Mora (2012, p. 204)— que parece ser que el deterioro de una específica zona de la corteza prefrontal hace que se pierda capacidad para planificar el futuro, seguir reglas sociales y cursos de acción ventajosos para la supervivencia, entre otros efectos. Existen también estudios mencionados por Triviño que señalan que el daño

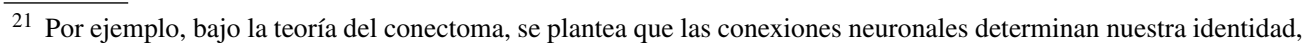
por lo que la diferencia entre las mentes derivaría de las diferencias entre sus conectomas, lo que de repente podría explicar la personalidad, el coeficiente de inteligencia y quizás hasta nuestros recuerdos (Seung, 2012, pp. 16-18).

22 «Motivada por el descubrimiento de que podemos crear nuevos circuitos neuronales en la edad adulta, se ha generado en el ámbito de la neurociencia una auténtica revolución, gracias también al reciente descubrimiento del proceso de la neurogénesis: la capacidad del cerebro de crear nuevas neuronas» (Perlmutter y Villoldo, 2011, p. 135).

${ }^{23}$ En 1948, a la edad de 25 años, trabajaba como capataz de construcción de un ferrocarril, cuando una explosión hizo que una barra de hierro del tamaño de una escoba le atravesara el rostro y la cabeza desde la mejilla izquierda hasta el cráneo; atravesó completamente su lóbulo frontal, y la barra salió despedida por el cráneo hasta más de 20 m. Sorprendentemente, Gage recuperó la consciencia y hasta pudo andar hasta la carreta que lo llevó al pueblo para que lo atendieran. Su sobrevivencia fue milagrosa, su tratamiento fue complicado, pero finalmente fue dado de alta a los 2 meses. Sin embargo, en poco tiempo empezó a cambiar su personalidad: se convirtió en un tipo grosero y mal educado, a tal punto, que los que lo conocían decían que ya no era el mismo (Narváez Mora, 2014, pp. 136-137). Gage sufrió el síndrome orbitofrontal (Redolar Ripoll, 2014, p. 34).

${ }^{24}$ Lo más interesante del Neuroderecho para la Filosofía del Derecho — acota Narváez- sería la aparición en el año 2004 del trabajo editado por Brent Garland (2004), que contiene artículos del «padre» de la neurociencia cognitiva, Michael S. Gazzaniga, obra importante no solo por dar un mayor auge a las discusiones que vinculan Neurociencia y Derecho sino porque desde entonces: «el tema de fondo lo constituye el tipo de transformaciones que las concepciones y teorías jurídicas, tanto dogmáticas como propiamente filosóficas, podrán llegar a sufrir a partir de los descubrimientos neurocientíficos, con las consiguientes repercusiones prácticas. Ya no se trata de cómo psicólogos y juristas van a crear vocabularios comunes para la comprensión de la idea de lesión cerebral, sino de cómo la creación y aplicación de pautas jurídicas pueden guiarse por descubrimientos neurocientíficos punteros» (Narváez Mora, 2014, p. 128).
} 
en la corteza prefrontal ventromedial aumenta en forma significativa el uso de juicios utilitaristas/impersonales (Triviño Mosquera, 2014, pp. 35-36).

Nadie nos programa como a una computadora, pero sabemos actualmente que contamos con las neuronas espejo para aprender y, sobre todo, interrelacionarnos, pues ellas tienen que ver con la empatía, con el poder comprender al otro vivenciando sus estados mentales (miedo, pena, alegría, etc.). Descubiertas en 1989 por Giacomo Rizzolatti $^{25}$, constituyen uno de los descubrimientos científicos más importantes de los últimos tiempos: explican desde por qué bostezamos cuando alguien bosteza, hasta los problemas del autismo o el síndrome de Asperger y la propia moral ${ }^{26}$.

Empero, lo más importante, acaso, tiene que ver con el conocimiento mismo de la esencia misma del ser humano: nuestra libertad, amenazada de pronto con volverse una ilusión.

\section{¿Quién manda a quién?}

En los orígenes del determinismo neurocientífico, puede citarse a los científicos alemanes Kornhuber y Deecke, cuyos experimentos parecen constatar la existencia de un «potencial de disposición no consciente» (Bereitschaftspotential) o «potencial de expectativa» que precede a los actos voluntarios más o menos un segundo antes (Cortina, 2014, p. 18).

Kornhuber había demostrado, midiendo la actividad eléctrica del cerebro, que antes de que las personas movieran un dedo había previamente una diminuta alteración en el registro eléctrico cerebral, un segundo antes de que la persona hiciera dicho movimiento voluntariamente.

Teniendo en cuenta dichos antecedentes, en Estados Unidos, en los años 80, Benjamín Libet hizo otro experimento: solicitó a un grupo de voluntarios conectados a unos electrodos que levantaran un dedo siempre que sintieran el impulso de hacerlo. Confirmó, entonces, la existencia del «potencial de disposición» del que hablaba Kornhuber, un segundo antes de que la persona levantara el dedo. Hasta allí, todo era

\footnotetext{
25 «Para Giacomo Rizzolatti: la existencia de las neuronas espejo es la demostración de que somos seres sociales y que estamos diseñados para estar unos con otros, para aprender por imitación» (Jiménez Vélez y Robledo Toro, 2010, p. 10).

26 Véase: Bartra (2011, p. 5), Straehle Porras (2013, p. 103-110).
} 
lógico, pues es entendible que, entre el momento en que nuestro cerebro decide hacer algo y el momento en que efectivamente lo hace (por ejemplo, mover un brazo), haya un breve tiempo.

Pero el experimento no quedó allí, pues, luego, Libet comparó el tiempo que le llevaba a la persona decidir el movimiento con el potencial de disposición, y descubrió que dicho potencial no aparecía después de que la persona sintiera el impulso de levantar el dedo, sino nada menos que $200 \mathrm{~ms}$ antes; de este modo, como destaca Kandel, Libet era capaz de predecir lo que el sujeto iba a hacer antes de que él mismo se diera cuenta de que lo había decidido (Kandel, 2007, pp. 447-448).

Fue Libet entonces quien despertó el debate en torno al libre albedrío, al plantear que ese potencial era anterior a la propia conciencia a la hora de tomar una decisión. Como dice Cortina, «Libet quería demostrar con ayuda de la lectura cerebral que nuestra voluntad es libre y, para su desconsuelo, sus experimentos parecieron refutar al principio esta hipótesis, y solo más tarde pudo matizar sus conclusiones. Pero tal vez lo más importante de sus experimentos es que desencadenaron una encendida polémica que sigue hoy muy viva» (Cortina, 2014, p. 18) ${ }^{27}$.

En palabras de Feijoo Sánchez (2011, p. 5), lo que demuestra Libet es que «no hacemos en realidad lo que hemos decidido racionalmente, sino que racionalizamos lo que nuestro inconsciente nos ha impulsado a hacer» ${ }^{28}$.

Agrega Cortina (2014, p. 19) que «de estos experimentos parece concluirse, pues, que si hablamos de acciones libres solo cuando un sujeto las elige conscientemente, entonces no cabría hablar de libertad, porque el potencial de disposición antecede a la

\footnotetext{
$\overline{27}$ Concretamente, Libet midió la actividad cerebral que se da durante ciertos movimientos voluntarios de las manos y averiguó que «antes de que se produjese el movimiento de la mano (entre 500 y 1.000 ms antes), había un conjunto de actividades cerebrales (el «potencial de preparación») y añadió que ya antes de que el sujeto tomara conciencia de su decisión de mover la mano, «su cerebro ya estaba activo, es decir, el potencial de preparación estaba ya presente»: el tiempo entre el comienzo de dicho potencial y el momento de la decisión consciente era de unos 300 ms. Entonces: «Si el potencial de preparación del cerebro se inicia antes de que seamos conscientes de tomar la decisión de mover la mano, parece que el cerebro conoce las decisiones antes de que seamos conscientes de ellas» (Gazzaniga, 2006, p. 103).

${ }^{28}$ Para Symington (2012, p. 80) «La importancia de este descubrimiento, que ha sido reproducido en varios experimentos posteriores con tecnología de scanner de resonancia magnética, es que los sujetos no estaban conscientes de la decisión que habían tomado, sino una tercera parte de un segundo después de que se hubiera registrado la disponibilidad potencial cerebral. Por lo tanto, dicho descubrimiento implica la iniciación del proceso mental que prepara para el acto voluntario, antes de que aparezca la conciencia voluntaria para actuar». Estudios de Michael Platt y Paul Glimcher, de la Universidad de Nueva York, y del propio Gazzaniga, entre otros trabajos, ratifican la idea de que el cerebro actúa por su cuenta antes de que seamos conscientes de sus acciones (Gazzaniga, 2006, p. 104-105).
} 
decisión consciente, la fuente de nuestras acciones estaría en algo — el inconscientesobre lo que no tenemos ningún control».

Si nuestra existencia está condicionada en buena parte por profundos procesos químicos y biológicos, si las decisiones que tomamos se generan en nuestro inconsciente antes de que tomemos consciencia de ellas, si nuestras decisiones conscientes terminan siendo un fruto de nuestro inconsciente, sería entonces necesario revisar los clásicos criterios para determinar la responsabilidad. Como dice Pauen (2002) «la conciencia y la autodeterminación desempeñan un papel central en cuestiones jurídicas y éticas fundamentales. Todo nuestro sistema de derecho se basa en el presupuesto de que podemos responder de nuestros actos. Si no fuera verdad, estaríamos obligados a realizar cambios fundamentales en dicho sistema».

\section{Dos pesos pesados en pugna: determinismo vs. libertad}

Nuestra conducta no puede reducirse a un solo gen, ni se puede reducir todo a los genes. Somos más que eso ${ }^{29}$. Como señala con acierto Carrara (2010) «los genes no producen malas personas: los genes producen proteínas»; y es que no podemos sobredimensionar el valor de los genes y caer en visiones deterministas que desconocen el valor de la libertad.

No podemos caer en un reduccionismo neurobiológico. El amor, la fe, la solidaridad, no son una simple cuestión química o una actividad neuronal ${ }^{30}$. Aún Wilson, el padre de la sociobiología, manifiesta: «Mi hipótesis es que nuestros genes nos predisponen a un determinado comportamiento más que a otro, sin que haya automatismo» (Sorman, 1995, p. 71).

Por su parte, Straehle (2013, p. 115) considera que «el hombre es un ser que no está sujeto a su información genética, porque hay una plasticidad potencial que se realiza constantemente mediante la interacción con los demás».

\footnotetext{
29 «No somos, no podemos ser, las marionetas de nuestros genes que dictan todo lo que hacemos y lo que haremos. Tenemos la facultad del libre albedrío que nos permite, en cada momento, hacer lo que se nos atoja y dirigir nuestro futuro como nos parezca. Todo el funcionamiento de nuestra sociedad se basa en esas premisas» (Ureta, 2009, pp. 36-37).

${ }^{30}$ Como dice Erickson, «Just about everything that is even tangentially linked with human affairs is reported to have some sort of neuro-salience. From the type of cars we drive and the people we vote for to understanding the roots of moral thought, nothing is safe from the reductions of neuroscience» (Erickson, 2016, p. 2).
} 
Si bien una característica básica del cerebro es que, en tanto que el plan básico de su organización está predeterminado por nuestros genes, «el plan general es modificado de manera sustancial por las influencias ambientales durante la vida» (Solms y Turnbull, 2005, pp. 10-11). Muchos rasgos no están totalmente codificados en los genes, «el entorno y el azar influyen también en la determinación de los rasgos y de la conducta» (Gazzaniga, 2006, p. 103).

Somos, pues, el producto de una compleja interrelación entre nuestros genes, la relación con nuestro entorno (desde nuestras experiencias hasta el medio ambiente) ${ }^{31}$ y los procesos físicos de nuestro desarrollo mental, en una interacción particularmente dinámica y trascendente, en la que tienen también un papel protagónico el lenguaje y la cultura ${ }^{32}$.

Vistos los estudios de Libet y otros posteriores, descubrimos entonces que nuestras decisiones no son tan libres como pensábamos, existen ciertos condicionamientos que nos anteceden. Decidimos antes de ser conscientes de nuestra decisión. ¿Significa eso que no existe la libertad? La respuesta es que la libertad, a pesar de todo, sí existe.

Un argumento para sustentar esta pervivencia de la libertad es que, de todos modos, siempre tenemos una capacidad de veto, de modo que la libertad podría definirse entonces como la capacidad de decir «no» a nuestros impulsos, a nuestras decisiones primigenias ${ }^{33}$.

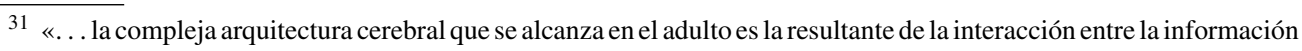
contenida en los genes, los procesos celulares que participan del neurodesarrollo y la interrelación del sujeto con el entorno» (Vásquez, G.H., Boullosa, Ó y Hadid, E., 2012, p. 91). Nuestro cerebro «alcanza su desarrollo gracias a la interacción con el medio en el que se desenvuelve; es decir, aprende de las experiencias sociales, se regula a través del feedback positivo o negativo que recibe del entorno, se organiza y reorganiza cuando las situaciones lo exigen» (Gutiérrez de Piñeres, 2013).

32 Sobre la importancia de la cultura indica Straehle Porras (2013, p. 117) que «no solamente somos un paquete de neuronas, dado que formamos parte de una cultura y de una sociedad que nos constituyen y transforman sin cesar». Por su parte, Bartra opina que nuestras decisiones «libres» son un proceso que ocurre en lo que llama nuestro exocerebro, entendido como conjunto de redes que unen a ciertos circuitos neuronales con una parte de las estructuras culturales (Bartra, 2011, p. 4).

33 «Desde el punto de vista neurocientífico, la esencia del «libre albedrío» parece ser —lo cual es bastante irónicola capacidad de inhibición, la capacidad de escoger el no hacer algo. Lo que distingue a los seres humanos más que cualquier otra cosa de sus más cercanos parientes primates es el desarrollo de un sistema más elevado del «yo», organizado fundamentalmente en mecanismos inhibitorios», mecanismos que reposan en los lóbulos prefrontales y que nos permiten suprimir las compulsiones primitivas y estereotipadas codificadas en nuestra memoria cerebral y heredada, por lo que dichos lóbulos frontales inhibitorios «pueden ser considerados, con alguna justificación, como la esencia misma de nuestra humanidad (Solms y Turnbull, 2005, p. 283). Estos lóbulos (que se ubican detrás de la frente) son los que nos permiten razonar, tomar decisiones, relacionarnos con los demás, controlar nuestros impulsos, etc.
} 
Sin embargo, esta idea nos parece aún insuficiente para comprender la libertad en toda su dimensión. En primer término, ese inconsciente, que por lo menos a veces parece decidir antes que nuestro consciente, es también parte de nuestro yo.

Por otro lado, frente al intento de encontrar una respuesta material que explique todo nuestro ser, creemos con Planck que hay un punto en el incomensurable mundo de la mente y la materia en el que la ciencia es inaplicable, no solo sobre bases prácticas sino también lógicas, y que permanecerá siempre insondable: es el ego individual, ese pequeño punto en el reino universal del ser donde ningún poder externo del destino puede tener dominio (Planck, 1961, p. 169).

Debemos a Libet y otros pensadores el saber que no somos tan libres como pensábamos, pero aparece entonces aquí la mecánica cuántica para intentar explicarnos mejor lo que somos a partir de ese pequeño espacio, acaso infinitesimal ${ }^{34}$. El hombre está determinado por una serie de cosas, que lo condicionan hasta cierto punto mecánicamente, pero, al final, siempre tiene la posibilidad de decidir ${ }^{35}$, y ese diminuto punto, por insignificante (o inexistente) ${ }^{36}$ que parezca, imposible acaso de demostrar, como también de recusar categóricamente, es capaz de alterar el universo de nuestra caótica existencia ${ }^{37}$, que no es sino una forma de referirnos a lo que llamamos libertad.

Finalmente descubrimos que la impredecibilidad no es un aspecto esencial del universo, sino más bien expresión de nuestra incapacidad tecnológica o intelectual (con lo que el indeterminismo cuántico no es ontológico, sino epistemológico ${ }^{38}$ ) igualmente indiferente, pues el libre albedrío no es un fenómeno físico. En todo

\footnotetext{
${ }^{34}$ Rabindranath Tagore buscaba encontrar en el universo un espacio para la libertad, y entonces pensaba que el azar a nivel infinitesimal — la incertidumbre que rige en el nivel subatómico—, descubierto por los físicos, era una prueba de que nuestra existencia no está predeterminada (Bartra, 2011, p. 1).

35 Y es que la libertad — como dice Straehle Porras (2013, p. 14)- «se sostendría sobre causas que facilitarían la decisión sin determinarla».

36 «... según nuestros conocimientos científicos actuales, no hay manera de encontrar el espacio físico en el que colocar el libre albedrío —la causa incausada— (Eagleman, 2014, p. 201).

37 Como explica Ramón María Nogués, en una interesante entrevista, «Actualmente muchos eminentes neurólogos piensan que la complejidad del sistema neural del cerebro permite situar el funcionamiento cerebral humano dentro de los sistemas caótico-deterministas que se caracterizan por un comportamiento poco predecible que admite diversas soluciones. El cerebro generaría la base comportamental básica de nuestras pulsiones y emociones y este mismo cerebro gozaría de una cierta capacidad de reorientación de estas pulsiones y de la facultad de mostrar «tarjeta roja» (es el símil que utilizaba Libet) a una conducta vivida o percibida como no adecuada. Esta capacidad de modular el margen de indeterminación disponible correspondería a lo que consideramos la libertad» (Véase la entrevista completa en: http://www.tendencias21.net/La-libertad-humana-desde-la-perspectiva-de-la-neurociencia_a42519.html).

38 Para más detalle sobre esta distinción, véase Muñoz (2015, p. 73).
} 
caso, quién sabe si acaso Dios no juega a los dados, sino que más bien nos los presta para que los tiremos.

Volviendo a los predios de la neurociencia, podemos decir, con lo expuesto hasta aquí, que la ética no tiene una base cerebral. Siguiendo a Cortina y Álvarez Díaz (2013, p. 380), consideramos que una cosa es que existan bases cerebrales de la moral y otra que pueda hablarse de un fundamento moral de la ética; es decir, no es lo mismo condición necesaria que condición suficiente.

Gracias a los avances de la neurociencia, podemos conocer mejor las bases neurológicas de nuestra conducta, pero, de todas maneras, «la labor de una fundamentación de la ética seguirá requiriendo de la filosofía» (Álvarez Díaz, 2013, p. 380).

Podemos decir, parafraseando a Carl Jung, que en cada uno de nosotros todavía hay otro al que no conocemos del todo (Eagleman, 2014, p. 17). Más aún si «los detalles de la naturaleza de los procesos neuronales que inciden en la toma de decisiones está aún por determinar» (Churchland, 2012, p. 183).

\section{Promesas jurídicas de la neurociencia}

Dentro de las posibilidades que puede ofrecer la neurociencia para una mejor comprensión y aplicación del derecho, y que deben evaluarse detenidamente (tarea que escapa a la extensión de este estudio) pueden mencionarse:

1) Facilitar la determinación acerca de si una persona cometió un delito o no, a través de la lectura del cerebro, examinando su actividad. Empero, debe tenerse en cuenta que, al menos por ahora, «la mayoría de los neurocientíficos opinan que el estudio de escáneres cerebrales puede orientar hacia una visión general de las raíces de la violencia, pero que las neuroimágenes individuales carecen de la especificidad necesaria como elemento de prueba» (Styx, 2014, p. 7).

2) Replantear el tema de la responsabilidad penal, a partir de la revisión del concepto de libertad.

3) Usar fármacos para modificar el comportamiento de delincuentes peligrosos.

4) Determinación más precisa de las causas y efectos de las adicciones, y elaboración de nuevos fármacos para enfrentarlos. 
5) Reemplazar con mejores medios los actuales detectores de mentiras, teniendo en cuenta su porcentaje de inexactitud y su posibilidad de evadirlos ${ }^{39}$.

6) Evaluar y definir de mejor manera los casos de incapacidad.

7) Mejorar la conceptualización del estado de conciencia de pacientes en estado de coma o vegetativo, y reducir así los riesgos de error en la desconexión de personas supuestamente muertas.

8) Usos para el tratamiento de las adicciones.

9) Optimizar la selección de jurados, confirmando la ausencia de sesgos, teniendo en cuenta que, a través de la neurociencia, se podrían detectar casos de «racismo inconsciente» y evitar prejuicios discriminatorios (Symington, 2012, p. 74) ${ }^{40}$.

10) Prevenir la comisión de delitos, prediciendo futuros actos criminales a través de exámenes con neuroimágenes ${ }^{41}$.

\section{Discusión}

No obstante sus vertiginosos avances, hay quienes se plantean si debe dejarse de lado la euforia inicial respecto a la neurociencia, la cual suele ser gentilmente acogida en los medios de comunicación, ávidos de noticias espectaculares ${ }^{42}$, que cae a veces en una neuromoda; es importante, asimismo, tener cuidado con intereses económicos subalternos o meros afanes de protagonismo.

Atraídos por la neurociencia, debemos tener cuidado de no caer en un neuroesencialismo, como una suerte de determinismo neurológico (Straehle Porras, 2013, p. 108), ni volver a las viejas posiciones lombrossianas que negaban la libertad.

Observa Santander, por ejemplo, que debemos ser cuidadosos al realizar estudios de fMRI y otras técnicas de neuroimagen, para ver qué tan confiables son; en algunos estudios, por ejemplo, el tamaño de la muestra podría activar nuestras alarmas

\footnotetext{
${ }^{39}$ Los detectores de mentiras pueden ser engañados por sociópatas que no muestran remordimiento sobre sus acciones; existen los casos del doble agente de la CIA Aldrich Ames o el asesino en serie Gary Ridgway; en el 2003 la Academia de Ciencias de EE. UU. publicó una lista de todas las formas mediante las cuales podía ser engañado un detector de mentiras y personas inocentes calificadas como mentirosas (Kaku, 2015, p. 108).

${ }^{40} \mathrm{El}$ tema debe analizarse con sumo cuidado, pues se trata de cuestiones que científicamente no pueden definirse con absoluta objetividad y porque además se correría el riesgo de que en nombre de la lucha contra la discriminación se termine discriminando.

41 «El objetivo del Derecho penal es la prevención de los delitos, pero (...) este objetivo solo se puede alcanzar a través del marco precisado por la pena adecuada a la culpabilidad y a las necesidades del tratamiento preventivo especial del delincuente» (Pérez Manzano, 2011, p. 32).

42 Como el caso de la noticia del llamado «efecto Mozart» que aseguraba que oír la música del genial compositor podía aumentar la inteligencia de los bebés, y que se acabó desinflando.
} 
académicas. Anota la misma autora que uno de los grandes problemas con el fMRI y otros no es que detecten la actividad cerebral, sino que miden el flujo de oxígeno en la sangre, no la actividad cerebral en sí (Santander García, 2014, p. 44-45).

Asimismo, debe tenerse cuidado con la interpretación de los datos, pues el hecho de que podamos ver en un experimento que una región del cerebro se activa, no nos dice con certeza si tiene que ver directa o indirectamente con la conducta estudiada (Triviño Mosquera, 2014, p. 39).

Es importante mirar las cosas con cautela, evitando que la atribución de un papel «mesiánico» a los avances y aplicaciones neurocientíficas (Ruiz Martínez-Cañavate, 2015, p. 1274) distorsione furtivamente la naturaleza y fin del derecho, y nos remonte a la idea de que hay criminales innatos, «ya no por el tamaño de su cráneo sino por sus características cerebrales» (Symington, 2012, p. 88).

\section{Conclusiones}

La neurociencia puede permitir comprender mejor nuestra mente tanto en la interpretación como en la aplicación del derecho; de la mano de la bioética, es una oportunidad para «refinar nuestros razonamientos ético-jurídicos y establecer nuevos patrones y criterios metodológicos sobre cimientos más firmes» (Kaku, 2015, p. 29).

Los estudios sobre neurociencia son todavía muy tempranos, en la mayoría de sus aspectos, para tentar conclusiones definitivas, por lo que cualquier abordaje debe ser prudente ${ }^{43}$. Sin perjuicio de dicha actitud, puede avizorarse que los nuevos conocimientos generarán profundos cambios y el derecho debe tener una actitud atenta y abierta.

Determinada nuestra existencia por muchos factores, igual seguimos siendo actores de nuestro destino. «Las neuronas son nuestras, el cerebro es nuestro, pero las neuronas no piensan, pensamos nosotros. El cerebro no es la mente. El cerebro es la infraestructura fisiológica de la mente» (Arango Restrepo, 2014, p. 167).

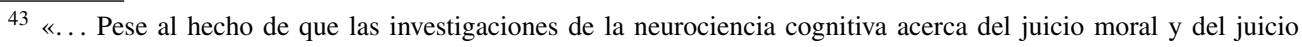
normativo en el derecho y en la justicia todavía se encuentran en una etapa muy precoz, su utilidad es indudable. Con una condición; la de tomarlas en cuenta con mucha prudencia. Los hallazgos neurocientíficos servirán para alcanzar un mayor conocimiento acerca de la naturaleza humana, pero este no garantiza, por sí mismo, valores morales como puedan ser un mayor respeto a la vida, a la igualdad y a la libertad humanas» (Fernández, s/a., p.1).
} 
No se trata de caer en un neorreduccionismo, por el que la ética solamente tuviera una base cerebral, ni tampoco un neuroescepticismo que desconoce el papel de la neurociencia.

Solo una pequeña parte de nosotros escapa a los mecanicismos deterministas, pero, aun así, es posible hablar de actos libres, por más que subyazgan estructuras neuronales, químicas y físicas (Bartra, 2011, p. 4).

Creemos que, ciertamente, como sostiene Gazzaniga, la neurociencia aportará nuevos modos de entender la conducta, pero debemos comprender que, aunque la causa de un acto sea explicable en términos de funciones cerebrales, esto no significa que la persona sea exculpable, y es que, mientras los cerebros son mecanismos automáticos, los individuos son agentes con responsabilidad personal, libres para tomar sus propias decisiones (Gazzaniga, 2006, p. 101).

La inquietud jurídica por preservar valores fundamentales no puede justificar de ninguna manera negar la importancia de la tecnología, sino más bien hacer el mejor uso de ella, teniendo en cuenta el «principio de autotelia», desarrollado por Miró Quesada Cantuarias (1992, p. 121), siguiendo las ideas de Kant, conforme al cual cada persona debe ser tratada siempre como un fin en sí, y no como un medio.

Es de tener en cuenta también, siguiendo a Braun (2014, p. 34) que «las preocupaciones sobre la biologización de los conceptos éticos no tienen por qué empobrecer la discusión en el campo ético. Todo lo contrario. Conforme aparece más información empírica de lo que somos y somos capaces de hacer, tendremos que reformular nuestras suposiciones tantos metafísicas como metodológicas».

Queda claro que nuestra conducta no puede reducirse a mera biología o química: eso sería negar nuestro propio ser y trascendencia. El ser humano, por definición, más allá de sus múltiples condicionantes, es un ser libre y racional, lo que es inseparable del reconocimiento del libre albedrío (Fernández Sessarego, 2013).

Si reducimos las conductas a simples expresiones biológicas, a mera genética, nadie sería responsable de lo que hace y tendríamos que terminar reemplazando prisiones por laboratorios y sustituir genes en lugar de modificar conductas (Marinoff, 2004, p. 73-74). 
El neuroderecho no debe apresurarse a la hora de confiar en los resultados del examen del cerebro (Straehle Porras, 2013, p. 113). Y es que, como dice Llinás (2002, p. 304) «la mente no necesariamente es una propiedad únicamente biológica».

Parece claro que «la moralidad no tiene una zona cerebral asociada» y que un escáner nos podrá dar cuenta de cómo reacciona nuestro cerebro al realizar ciertas acciones, pero de ninguna manera nos va a decir qué es lo bueno ni qué es lo malo, ni como debemos comportarnos (Santander García, 2014, p. 46).

El que estudios realizados con pacientes con lesiones cerebrales y que el avance de las técnicas de neuroimagen nos permitan saber que a la hora de decidir intervienen tanto factores cognitivos - los cuales se encargan de procesar los estímulos presentes, de recordar experiencias y de valorar las posibles consecuencias que pueden tener las decisiones - como factores de tipo emocional (Redolar Ripoll, 2014, p. 735), no disminuye, sino que enriquece nuestra visión del ser humano.

Finalmente, así como se ha distinguido con acierto la existencia una ética de la neurociencia y una neurociencia de la ética, podemos postular la idea tanto de un neuroderecho como de una neurociencia del derecho. Lo primero, para hacer referencia al marco legal y los problemas jurídicos asociados al quehacer neurocientífico y la manipulación del cerebro; lo segundo, para referirnos al impacto del conocimiento neurocientífico en la comprensión y mejor ejercicio del derecho.

En ambos casos, ante los avances de la técnica y las necesidades de nuestro tiempo, requerimos de una filosofía de la tecnología, como plantea Jonas (1997, p. 15), junto con una ética de la responsabilidad, que sustente nuestra libertad, que honre nuestra condición humana.

Dicha cuestión ética se torna más importante y compleja en nuestro tiempo por el hecho de que las tecnologías ya no operan únicamente sobre el mundo exterior, sino sobre el propio ser humano, lo que le otorga a la bioética — en este caso, a partir concretamente de la neurociencia- una trascendencia e impacto jamás tenido.

Aquella neuroética que hemos de seguir construyendo solo podrá plasmarse en el derecho en cuanto sea compatible con los derechos humanos y la razón, mirando a la ciencia y a la técnica como medios al servicio del ser humano para alcanzar el progreso —en el sentido que le da Agazzi (1996, p. 16-18) al término-, lo cual 
demanda una actitud de compromiso que refuerce y renueve nuestra esperanza, en un contexto valorativo, para mantener el sentido de nuestra existencia.

\section{Conflicto de intereses}

El autor declara no tener ningún conflicto de intereses.

\section{Agradecimientos}

La presente investigación ha sido realizada con el auspicio del Instituto de Investigación Científica de la Universidad de Lima, contando con la valiosa colaboración del estudiante Branco Monzón Gutiérrez, alumno de la Facultad de Derecho de la misma universidad.

\section{Referencias}

Agazzi, E. (1996). Ciencia y racionalidad para el futuro del ser humano. Contrastes. Revista Interdisciplinar de Filosofía., Vol. I, 7-18, 1996

Álvarez Díaz, J. A. (2013). neuroética como neurociencia de la ética. Revista neurología, 57, 374-382.

Álvarez del Blanco, R. (2011). neuromarketing. Fusión perfecta (2. ${ }^{a}$ Edición). Madrid: Financial Times Prentice Hall.

Andruet (h), A. S. (2004). Bioética, derecho y sociedad. Conflicto, ciencia y convivencia. Córdoba: Alveroni Ediciones.

Arango Restrepo, P. (2014). La neuroética, problema emergente en la bioética. Revista Lasallista de Investigación, 11(1), 161-168.

Bartra, R. (2011). Antropología del cerebro: determinismo y libre albedrío. Salud Mental, 34(1), 1-9 (enerofebrero de).

Berger, M. (2015). El poder de las marcas. Revista Mente y Cerebro N. 74.

Braun, R. (2014). La neuroética y la naturalización de la filosofía moral. Persona, 33-51 (enero-diciembre).

Cardinali, D. (2007). neurociencia aplicada. Sus fundamentos. Buenos Aires: Editorial Médica Panamericana.

Carrara, A. (2010). Neuroderecho: ¿qué hay detrás de esta nueva etiqueta [consultado Ene 2017]. Disponible en: http://www.iustitiae.tomas-moro.org/miscelanea/articulos-miscelanea/ neuroderechoquehaydetrasdeestanuevaetiqueta.

Churchland, P. (2012). El cerebro moral. Barcelona: Paidós.

Cortina, A. (2014). La indeclinable libertad de los ciudadanos: neuroética y neuropolítica. En De la Torre Javier (Ed.), neurociencia, neuroética y bioética. Madrid: Universidad Pontificia Comillas.

Del Brío León, M. A. (2011). Bioética y neuroneuroneurociencia: neuroética. Revista de Bioética y derecho, (21), 14-22 (Enero)

Eagleman, D. (2014). Incógnito (4. ${ }^{\mathrm{a}}$ ed.). Barcelona: Anagrama.

Elsevier Brain Research Report (2014). BRAIN SCIENCE Mapping the Landscape of Brain and Neuroscience Research. Disponible en: https://www.elsevier.com/_data/assets/pdf_file/0004/53455/ ElsevierBrainScienceReport2014-web.pdf 
Erickson, S. K. (2012). The limits of Neurolaw (June 4, 2011). Houston Journal of Health Law and Policy, 112 [consultado 15 Jul 2016]. Disponible en SSRN: https://ssrn.com/abstract=1857971

Estupinya, P. (2010). El ladrón de cerebros. Compartiendo el conocimiento científico de las mentes más brillantes. Barcelona: Random House.

Evers, K. (2010). neuroética. Buenos Aires: Katz.

Feijoo Sánchez, B. (2011). derecho penal y neurociencias. ¿Una relación tormentosa? InDret. Revista para el análisis del derecho.

Fernández, A. (s/a). Derecho y neurociencia. URBE et IUS: Newsletter N. ${ }^{\circ} 20$ [consultado 31 dic 2015]. Disponible en: http://www.monografias.com/trabajos-pdf900/derecho-y-neurociencia/derecho-y-neurociencia.pdf

Fernández Sessarego, C. (2013). Breves apuntes sobre el «proyecto de vida» y su protección jurídica. Revista de derecho de la Universidad César Vallejo, ${ }^{\circ}{ }^{\circ} 2$.

Fukuyama, F. (2002). El fin del hombre. Consecuencias de la revolución biotecnológica. Madrid: Ediciones B, S.A.

García García, E. (2014). neuropsicología del comportamiento moral. En J. De la Torre (Ed.), neurociencia, neuroética y bioética. (pp. 43-75). Barcelona: Universidad Pontificia Comillas.

Garland, B. (2004). Neuroscience ant the Law. Brain mind and the scales of justice. New York/Washington, D.C.: The American Association for the Advancement of Sicence and the Dana Foundation.

Gazzaniga, M. (2006). El cerebro ético. Barcelona: Paidós.

Gutiérrez de Piñeres, C. (2013). neurociencias, justicia y libre albedrío. Psicogente, 16(29) (Enero-junio).

Jiménez Vélez, C. A. y Robledo Toro, J. (2010). La Neuropedagogía y los comportamientos violentos. Nuevos hallazgos desde la neurociencia. Bogotá: Editorial Magisterio.

Jonas, H. (1997). Técnica, medicina y ética. Barcelona: Paidós.

Kaku, M. (2015). El futuro de nuestra mente. Lima: Penguim Random House.

Kandel, E. (2007). En busca de la memoria. El nacimiento de una nueva ciencia de la mente. Buenos Aires: Katz.

Llinás, R. R. (2002). El cerebro y el mito del yo. El papel de las neuronas en el pensamiento y el comportamiento humanos. Bogotá: Editorial Norma.

Marinoff, L. (2004). Pregúntale a Platón. Buenos Aires: Artes Gráficas Buschi.

Miró Quesada Cantuarias, F. (1992). Hombre, sociedad y política. Lima: Ariel-Comunicaciones para la Cultura.

Muñoz, J. M. (2015). Mecánica cuántica y libre albedrío: cinco cuestiones fundamentales. Revista Principia, 19(1), 65-92.

Narváez Mora, M. (2012). El impacto de la neurociencia sobre el Derecho: el caso de la responsabilidad subjetiva. En: Revista Telemática de Filosofía del Derecho, 15, 195-230 [consultado 8 Ene 2016]. Disponible en: http://www.rtfd.es/numero15/07-15.pdf

Narváez Mora, M. (2014). neuroderecho: el sentido de la acción no está en el cerebro. Revista de Teoría del derecho de la Universidad de Palermo, I(2), 125-148 (Noviembre).

Nevares-Muñiz, D. (2013). Deliberación en Bioderecho. Lumen, 9, 125-134.

Pauen, M. (2002). Cerebro y libre albedrío. Revista Mente y Cerebro, N. ${ }^{\circ} 1$.

Perlmutter, D. y Villoldo, A. (2011). Conecta tu cerebro. La neurociencia de la iluminación. Málaga: Editorial Sirio, S.A.

Planck, Max. (1961). ¿Adónde va la ciencia? (4. ${ }^{a}$ edición). Buenos Aires: Editorial Losada S.A.

Pérez Manzano, M. (2011). Fundamentos y fines del derecho Penal. Una revisión a a luz de las aportaciones de la neurociencia. InDret, Revista para el Análisis del derecho, 1-39.

Punset, E. (2011). Cara a cara con la vida, la mente y el universo. Conversaciones con los grandes científicos de nuestro tiempo (14.a reimpresión ed.). Barcelona: Ediciones Destino.

Redolar Ripoll, D. (2014). neurociencia cognitiva. Madrid: Editorial Médica Panamericana.

Restak, R. (2005). Nuestro nuevo cerebro. Barcelona: Urano. 
Ruiz Martínez-Cañavate, M. (2015). neurociencia, derecho y derechoderechos humanos. Revista de derecho UNED, 17, 1249-1278.

Santander García, C. A. (2014). neuroética hoy. Dilemata, (15), 41-50.

Savater, F. (2012). Ética de urgencia. Bogotá: Ariel-Editorial Planeta.

Searle, J. (1994). Mentes, cerebro y ciencia. Madrid: Ediciones Cátedra.

Seung, S. (2012). Conectoma. Barcelona: RBA Libros.

Solms, M. y Turnbull, O. (2005). El cerebro y el mundo interior. Una introducción a la neurociencia de la experiencia subjetiva. Bogotá: Fondo de Cultura Económica.

Sorman, G. (1995). Los verdaderos pensadores de nuestro tiempo. Bogotá: Seix Barral.

Straehle Porras, E. (2013). En busca de un fundamento crítico y social de la moral desde una perspectiva neurocientífica. Recerca, 13, 103-120 [consultado 19 jul 2016]. Disponible en: http://www.e-revistes.uji.es/ index.php/recerca/article/view/365

Styx, G. (2014). Disparé obligado por mi cerebro. Mente y Cerebro, 67, 7.

Suárez Bolesman, D. (2016). Entrevista a Paul Marasco. En: Diario El Comercio, edición del 15.06.2016, p. 21.

Symington, G. (2012). neurolaw: De la defensa judicial hacia un derecho penal del enemigo. Universidad Estud Bogotá (Colombia), 9, 67-99.

Triviño Mosquera, M. (2014). Mecanismos cerebrales en los juicios y decisiones morales. En J. De la Torre (Ed.), neurociencia, neuroética y bioética (pp. 27-41). Madrid: Universidad Pontificia Comillas.

Ureta, T. (2009). Entre la química y la historia: libre albedrío y determinismo. Theoria, 18(1), 35-41. Universidad del Bío Bío (Chile).

Vásquez, G. H., Boullosa, Ó. y Hadid, E. (2012). neurociencia. Bases y fundamentos (2.a ed.). Buenos Aires: Polemos.

Wolf, C. (2016). Modificar los recuerdos. Revista Mente y Cerebro N. ${ }^{\circ} 77$. 